\title{
Innovation policy for directing technical change in the power sector
}

Rob Aalbers

Victoria Shestalova

Viktória Kocsis 



\title{
Innovation policy for directing technical change in the power sector
}

\author{
Rob Aalbers ${ }^{\text {a) }}$ \\ Victoria Shestalova ${ }^{\text {b) }}$ \\ Viktória Kocsis ${ }^{c)}$
}

September 26, 2012

\begin{abstract}
This paper discusses policy instruments for redirecting technical change within the electricity sector to mitigate climate change. First, we unravel the mechanism behind directed technical change, explaining why markets may underprovide innovations in expensive renewable technologies in comparison to innovations in energy-efficient fossil-fuel generators. Subsequently, we characterize technical change in electricity generation technologies, stressing the heterogeneity of knowledge spillovers both within and between clean electricity generation technologies. We argue that there exists a rationale for a portfolio approach to innovation in the electricity sector, i.e., optimal innovation policies are neither fully generic nor fully specific; and they need to be adapted, in response to new information learned by the government. The existing innovation literature does not, however, provide a clear-cut answer for designing such a policy. We compare policy instruments and argue that public $R \& D$ support to clean technologies, either in the form of subsidies or prizes, seems to be the prime candidate for implementing non-generic innovation policy.
\end{abstract}

a) R.F.T.Aalbers@cpb.nl; CPB Netherlands Bureau for Economic Policy Analysis, P.O. Box 80510, 2508 GM The Hague, the Netherlands.

b) V.Shestalova@cpb.nl (corresponding author); CPB Netherlands Bureau for Economic Policy Analysis, P.O.Box 80510, 2508 GM The Hague, the Netherlands.

c) v.kocsis@ seo.nl; SEO Economic Research, Roetersstraat 29, 1018 WB Amsterdam, the Netherlands

Acknowledgement. This study is part of the research project 'Directed technical change and the environment' initiated by the Dutch Ministry of Economic Affairs, Agriculture and Innovation. We are grateful to the representatives of Dutch ministries and other institutions: Victor Joosen, Frans Duijnhouwer, Ben Geurts, Bert Knoester, Klaas-Jan Koops, Ewout Visser, and Herman Vollebergh, for their feedback during the project. In addition, we gratefully acknowledge the comments of our colleagues George Gelauff, Free Huizinga, Bas Straathof, and Henry van der Wiel on earlier versions of the paper. 


\section{Introduction}

In the electricity sector, technology choice is the prime determinant of $\mathrm{CO}_{2}$ emissions. ${ }^{1}$ Therefore, reducing the electricity sector's carbon emission boils down to the substitution of technologies with high emission factors, such as coal, by technologies with lower emission factors, such as natural gas or renewables. ${ }^{2}$ Alternatively, fossil fuel-fired capacity can be complemented by carbon capture and storage to lower emissions. Today, most low-carbon alternatives are still considerably more expensive than the traditional fossil-fuel based technologies (if we disregard energy-related taxes and subsidies), which stresses the need for cost-reducing innovation in clean power-generating technologies (hereafter: 'clean innovations').

However, two market failures impede clean innovations (e.g., Jaffe et al., 2005). The first market failure is associated with environmental pollution, and the second one is associated with the innovation and diffusion of new technologies. As major reasons for the second market failure, Jaffe et al. (2005) stress externalities in knowledge and adoption, and incomplete information. Although these externalities impede innovations in both dirty and clean technologies, they have a larger impact on innovation in clean technology, because of the interaction with the environmental market failure. As a result, clean technologies have historically been developed less than dirty technologies. This path dependency in the direction of technical progress locks the economy into the use of dirty technologies (Unruh, 2000 and 2002).

Acemoglu et al. (2012) formally relate the path dependency of technical change in the economy to policy instrument choice. ${ }^{3}$ In their model, a final good is produced by combining inputs of two sectors: clean and dirty. Path dependency arises because the knowledge accumulation process is sector-specific. Any clean (dirty) innovation builds on the existing knowledge stock in the clean (dirty) sector and adds to this knowledge stock. Since the economy has so far accumulated a larger knowledge stock on dirty technologies, innovation in dirty technology is more profitable than innovation in clean technology. Hence, in the absence of an innovation policy correcting for this 'gap' in innovators' profits, research efforts will always be directed at dirty technologies. Acemoglu et al. (2012) show that a combination of R\&D subsidies to clean research and pollution taxes is optimal for redirecting technical change towards the clean sector of the economy. Since recent empirical work corroborates the theory of directed technical change for the electricity sector (see, for example, Hascic et

\footnotetext{
${ }^{1}$ This becomes immediately apparent by comparing the emission factors associated with the dominant electricity generation technologies. For instance, according to IEA (2011), the implied emission factors from electricity and heat generation are 370 gram $/ \mathrm{kWh}$ for natural gas, 610 gram $/ \mathrm{kWh}$ for oil, and $840 \mathrm{gram} / \mathrm{kWh}$ for bituminous coal.

${ }^{2}$ Additionally, carbon emissions will decrease if demand for energy decreases, e.g., because of increased energy-efficiency of electric appliances. However, these energy-efficiency increases would then need to offset the overall increasing trend in the use of these appliances. According to the projections by the IEA (2009), world electricity demand is expected to grow at an annual rate of $2.5 \%$ until 2030, thus, there is still a need in reducing emissions in electricity production. The current paper considers the effect of energy-efficiency increases in electricity generation, but leaves out energy-efficiency in consumption.

${ }^{3}$ There exists a substantial endogenous-growth literature that relates technological change to instrument choice by modeling the innovation process in clean technology. See, e.g., Bovenberg and Smulders (1995, 1996); Goulder and Mathai (2000); Van der Zwaan et al. (2002); Popp (2004); Gerlagh et al. (2009).
} 
al., 2009, Lanzi and Sue-Wing, 2010, and Noailly and Smeets, 2012), ${ }^{4}$ we will use this theory as a starting point for our analysis of policy instruments to spur clean innovations in this sector.

Notwithstanding the general characterization of optimal innovation policy by Acemoglu et al. (2012), the practical question arises: how to apply the insights from this general theory in order to redirect technical change in power-generating technologies efficiently? First, we need to extend the scope of the analysis to incorporate multiple clean technologies, which are present in this sector. Secondly, Acemoglu et al. focuses on the case in which all innovations in clean technology have identical knowledge spillovers to all other clean innovations, which rules out differentiated R\&D subsidies for different clean technologies. Therefore we need to discuss what may happen if knowledge spillover patterns differ between clean technologies. Finally, we need to address information issues. For example, bringing into consideration asymmetric information between the government and firms makes the choice between ex ante subsidies and ex post rewards material (Wright, 1983). Our paper contributes to the economic literature by highlighting the effect of these additional aspects that are present in this sector and discussing how they may affect policy instrument choice. In doing this, we will also take into account the global character of the clean-innovation problem in the context of climate change mitigation. ${ }^{5}$

While there is a large theoretical literature on environmental policy instruments for spurring clean innovation and their adoption (e.g., emission and performance standards, emission taxes, or emission permits; see Requate, 2005), the most of this literature focuses either on particular instruments, or on the comparison of one such instrument against another. ${ }^{6}$ The instruments analyzed in this literature aim to reduce emissions, while spurring innovations at the same time. Indeed, empirical studies confirm that (especially stringent) environmental policies both reduce pollution and spur clean innovation (e.g., Vollebergh and van der Werf (2012) argue that more stringent environmental standards spur more radical clean innovations). Complementary to these insights about the composite effects of environmental policy instruments, there are also theoretical results suggesting that it may be more efficient to address market failures in the clean research market by additional instruments, such as R\&D subsidies. These results show that combining an environmental policy instrument - for example, an emission tax or permit - with such a subsidy can improve social welfare (Fisher and Newell, 2008, Golombeck et al., 2010, and Montero, 2011). Our paper follows that line of research and compares three compound policy options for spurring clean innovations. Each of these policy options will include a carbon tax (at least at the level of the current marginal damage) and some level of patent protection, as a 'basic policy': the carbon tax intends to solve the environmental market failure and the patent system solves the generic research market failure. Furthermore, in order to deal with the path-dependency issue, the basic policy is extended in one

\footnotetext{
${ }^{4}$ Another closely related empirical paper is Aghion et al. (2011), which considers the automobile industry. It finds that innovating firms build on their existing technology-specific knowledge stock to develop new innovations.

${ }^{5}$ Given that emissions in the power sector are linked to both climate change and air quality, there may be trade-offs and cobenefits from reducing both greenhouse-gas emissions, which accumulation causes climate change on a global scale, and local air pollutants. Here we mainly focus on global effects of climate policies. See Bollen et al. (2009) for the discussion of co-benefits of climate policies for air pollution.

${ }^{6}$ For example, command-and-control instruments, such as technological, emission and performance standards, are compared to market-based instruments, such as taxes and pollution permits.
} 
of the three alternative ways: (i) providing public R\&D to clean innovation; (ii) strengthening patent protection; or (iii) raising the carbon tax above the marginal emission damage level. It will be shown that - compared to the options of modifying patent protection or raising carbon taxes above the marginal damage level - public R\&D is likely to be more suitable for spurring innovation in clean electricity generation technologies.

The paper proceeds as follows. Section 2 introduces a simple example to explain the essence of the problem that arises with respect to clean innovations. The example explains why certain clean innovations in the electricity sector are likely to be underprovided by the market. By means of this example, we stress the importance of public support to innovations in emerging clean technologies, rather than innovations in energy-efficient fossilfuel technologies, and highlight the main challenges in policy design to achieve these innovations. Section 3 describes the context of the electricity sector in more detail. Since this sector produces a relatively homogeneous product $^{7}$ (except for the timing and location of generation), technical change in power-generating technologies mainly aims to reduce production costs. However, it will be shown that notwithstanding this uniform 'goal', technical change in the power sector displays considerable heterogeneity. This observation provides a rationale for considering more technology-specific innovation policies in this sector, as discussed in Section 4.

Subsequently, Section 5 applies this insight to compare policy options for spurring clean innovations, providing arguments in favor of public R\&D-portfolio approach to spur innovations in clean electricity-generating technologies. Section 6 concludes.

\section{Why do 'clean' technologies deserve additional support?}

In a recent paper, Acemoglu et al. (2012) show that subsidies to clean research are an indispensable ingredient to properly stimulate the development of clean technologies. These subsidies are indispensable in the sense that, without them, the switch to developing clean technologies will either occur too late or will be too costly. An important assumption driving their result is that knowledge spillovers in each technology type (clean and dirty) are both sequential and complementary. Here, sequential means that each innovation builds on the preceding innovation in the same technology type, i.e., innovators "stand on the shoulders of giants", whereas complementary means that knowledge spills over between firms within the same (either clean or dirty) technology type, but not between these types. To be able to fully apprehend the implications of this assumption for innovation policy, we present a simple example that explains why the current patent system provides insufficient incentives for innovation in clean electricity generation technologies. Furthermore, we discuss possible alternative policy measures.

Consider two periods, $t=1,2$. In each period at most one firm, which is randomly drawn from a pool of potential innovators, can innovate in a clean technology to reduce the production cost of this technology. Examples of such technologies are solar PV, onshore wind, and carbon capture and storage (CCS). For the ease

\footnotetext{
${ }^{7}$ For the sake of simplicity, we ignore the effect of product differentiation in the power market in the main analysis of this paper. Moraga-Gonzales and Pardon (2002) consider a model in which consumers differ in their valuation for the green features of the product and show that a technological subsidization of green technologies is still welfare improving in this case.
} 
of exposition, we assume that the randomly-drawn firm can only undertake one innovation, which is always successful. The innovation takes place at the beginning of the period and gives the firm instantaneous access to a new clean technology with a lower production cost, for which the firm obtains a perfectly-enforced, one-period patent. After this patent has expired, the patent's embodied knowledge spills over to the pool of potential innovators, enabling any of them to do a follow-on clean innovation. Thus, we assume that the second innovation builds on the first one and it can only be undertaken one period after the first innovation has been undertaken; and the new knowledge added in the first period improves the starting position of all the potential innovators in the second period.

The initial cost of the clean technology is $c$. Each innovation reduces this cost by $\delta$ : the cost of clean energy production decreases to $c-\delta$ after the first innovation; and to $c-2 \delta$ after the second innovation. For expositional purposes, we assume that the cost of the existing dirty technology equals zero and that the dirty technology cannot be improved upon, i.e., there is no innovation in the dirty technology. The electricity market is perfectly competitive, and the innovating firm can supply one unit of electricity in this period at the market price. The marginal pollution damage in the first period is zero, whereas the marginal pollution damage in the second period is above $c$. In other words, the clean technology will need to be employed in the second period, even if its costs remain high. Furthermore, we assume that the second-period carbon tax $t$ is set in accordance with the marginal pollution damage in that period, hence $t>c$. However, the first-period carbon tax may be set at or above the first-period marginal pollution damage. Figure 1 displays the costs of the clean technology in both periods together with the respective carbon taxes $\alpha t$ and $t$. Here, $\alpha(0 \leq \alpha<1)$ denotes the level of the carbon tax in the first period relative to that in the second period. Finally, we ignore discounting and to allow innovation to be profitable; we also assume that the cost reduction $\delta$ resulting from any innovation is larger than the cost $\theta$ to undertake the innovation, i.e., $\delta>\theta$.

\section{Figure 1 Innovation in clean technologies}

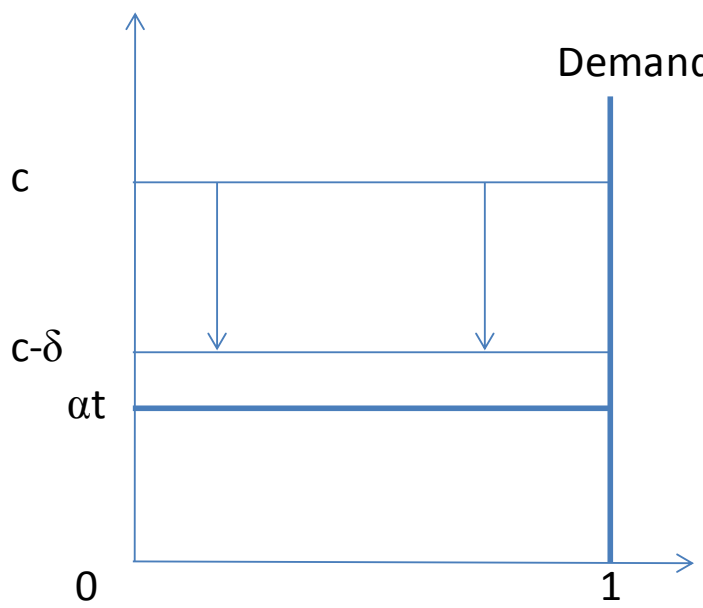

Period 1

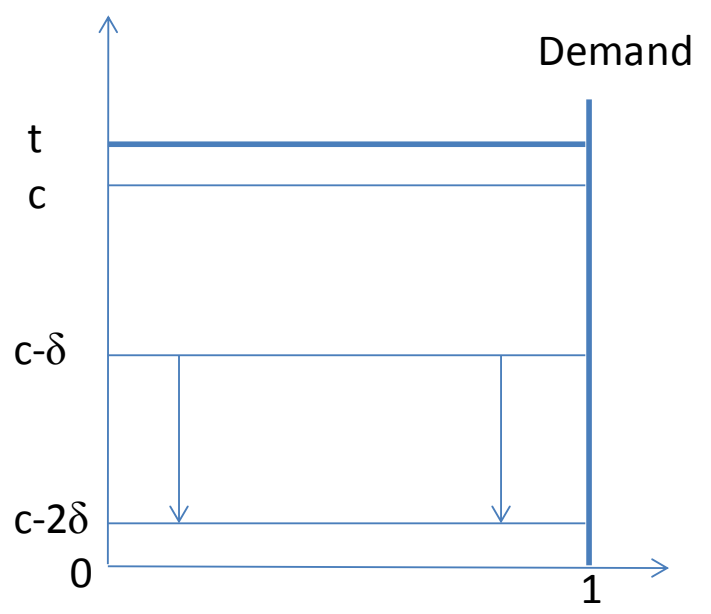

Period 2 
The social welfare is expressed as the difference between the total benefits (including the avoided environmental damage) and the total costs of clean innovation and production over the two periods. Its maximization shows that it is socially optimal to innovate in both periods provided that the second period benefit after both innovations, $t-(c-2 \delta)$, is larger than the cost of these innovations, $2 \theta^{8}$. Although the socially optimal strategy requires innovating in both periods, it is not socially optimal to use the clean technology in the first period because, in the first period, the cost of the improved clean technology is still larger than the marginal damage of pollution, $c-\delta>\alpha t$. In contrast, under a one-period patent, a private firm would only innovate in the first period if it could yield a positive profit, i.e., if $c-\delta+\theta<\alpha t$. This disparity between the social and private incentives to invest results from the inability of (one-period) patents to internalize knowledge spillovers from innovations that are not (almost) immediately used. So, our simple example suggests that clean technologies deserve additional policy support not because they are 'clean', but because they are too expensive to be used in the first period, while it is efficient to start to develop them in the first period in order to use them at a low cost in the second period. Since the incentives under patent protection depend crucially on the actual use of a technology during the lifetime of a patent, patents will provide insufficient incentives in this case. Thus, our example points out that relatively more expensive renewable technologies, such as solar PV, are more likely to suffer from this lack of incentives than relatively less expensive technologies, such as onshore wind.

Moreover, it also suggests that incentives for innovation in highly-efficient coal and gas power plants are sufficient, as first-period profits will be positive for these innovations. This is intuitive, since the profitability of innovations in the first period depends primarily on energy prices instead of carbon taxes.

Table 1 lists three policy options that could be used by the government to internalize the knowledge spillovers considered in our simple example. Here we assume that the first-period carbon tax is initially equal to zero to capture the idea that the current damage level is relatively low. First, an R\&D subsidy on clean research of at least $\theta$ will reimburse the innovation cost to the first-period innovator and, therefore, will fully internalize the knowledge spillovers. Second, a two-period patent will create sufficient incentives for the first-period innovator. To see this, notice that the total profit after two sequential innovations is positive: $t-(c-2 \delta)-2 \theta>0$. If the first-period innovator has obtained a two-period patent, he can license the technology for an amount slightly larger than $\theta$ to the second-period innovator, giving both innovators strictly positive profits. Finally, a firstperiod carbon tax of at least $c-\delta+\theta$ will induce innovation by yielding the first-period innovator a sales profit of $c-\delta+\theta-(c-\delta)=\theta$, which is just sufficient to recoup the innovation cost.

\section{Table 1 Polices that fully internalize knowledge spillovers $(\alpha=0)$}

\begin{tabular}{lll}
\hline Policy instrument & "Minimum" size & Welfare gain from clean innovation \\
Clean research subsidy & $\theta$ & $2(\delta-\theta)$ \\
Extending patents & at least two periods & $2(\delta-\theta)$ \\
Carbon tax & $c-(\delta-\theta)$ & $2(\delta-\theta)-(c-\delta)$ \\
\hline
\end{tabular}

\footnotetext{
${ }^{8}$ This follows from our assumptions on (i) the second-period carbon tax $t>c$; and (ii) the 'profitability' of the innovations $\delta>\theta$. From this it is easy to see that innovating twice achieves higher social welfare than innovating once or no innovation.
} 
Turning to optimal instrument choice, we observe from Table 1 that a "diffusion" instrument, such as carbon taxes, that induces innovation by encouraging its diffusion, is associated with lower welfare levels than pure "innovation" instruments, such as patents and research subsidies, that deal with the knowledge spillovers directly (cf. Acemoglu et al., 2012). Thus, our example highlights the importance of current policies for the development of clean technologies for the future. However, since our example has disregarded many of the electricity market's key characteristics, we cannot expect it to provide further reliable and robust insights into the issue of instrument choice. For instance, it is well-known that policy instrument choice depends on the pattern of knowledge spillovers between technologies (Acemoglu et al., 2012) and the presence of private information (Wright, 1983). As we focus on the electricity sector, we now provide a short summary of its main characteristics in terms of technologies, knowledge spillovers, and information problems.

\section{Key characteristics of innovation in electricity generation technologies}

We now turn to the key characteristics of innovation that, in our view, need to be considered in the design of government innovation policy in the electricity sector. First, we discuss how the presence of multiple, and often competing, electricity generation technologies influences the social value of innovations in these technologies. Second, we discuss the extent of knowledge spillovers between electricity generation technologies. Third, we address the role of information asymmetry between the government and innovating firms, and the extent of uncertainty that they both face about the innovation process.

\subsection{Multiple technologies}

Electricity generation technologies are imperfect substitutes in power supply. ${ }^{9}$ Consequently, innovations in one technology decrease the value of other technologies, because the - now cheaper - technology gains market share (or at least, the probability increases that this technology may gain market share in the future). ${ }^{10}$ Power generating technologies are imperfect substitutes for both technical and economic reasons. On the technical side, different electricity generation technologies exhibit a different ability to vary supply at short notice. At one extreme, wind and solar capacity have no ability to vary their supply at all; at the other extreme, gas-fired and modern coal-fired capacity have a relatively high ability to vary supply at short notice. As a consequence, wind and solar will be imperfect substitutes for gas-fired and modern coal-fired capacity. On the economic side, many electricity generation technologies tend to display decreasing returns, again implying that they are imperfect substitutes. These decreasing returns to scale may arise either from the use of exhaustible resources, such as natural gas, or the limited availability of 'suitable' locations, such as onshore locations where the wind is strong. Finally, electricity generation technologies are characterized by a different mix of fixed over variable costs. For example, although coal-fired generation is a perfect substitute for gas-fired generation for producing base load, it is an imperfect substitute for producing peak load, because coal-fired generation incurs higher fixed costs.

\footnotetext{
${ }^{9}$ Two technologies, A and B, are substitutes whenever the demand for technology A increases in response to an increase of technology B's cost. Conversely, two technologies are complements whenever the demand for technology A decreases in response to an increase of technology B's cost.

${ }^{10}$ In addition, there may be also direct knowledge spillovers between technologies, which we discuss in Section 3.2.
} 


\section{Figure 2 Example of (imperfect) substitute and complementary technologies}


Notice that, although it is generally true that technologies in the power sector are imperfect substitutes, some technologies are complements, implying that innovations in these technologies will increase the value of innovations in other technologies (see Figure 2). For example, cheaper storage increases the value of the intermittent electricity generation technologies, such as wind and solar. ${ }^{11}$ In the same manner, innovations in carbon capture and storage will increase the value of gas-fired and coal-fired generation. Finally, notice that, depending on circumstances, two electricity generation technologies can either be (imperfect) substitutes or complements. For instance, gas-fired and hydro capacity are substitutes for wind and solar capacity, whenever these technologies replace wind and solar. However, if they are used as back-up capacity, gas-fired and hydro capacity will be complementary to wind and solar capacity.

\subsection{Knowledge spillovers}

The empirical literature on energy patents shows that inventors 'stand on the shoulders' of their predecessors, and the knowledge spillovers are larger in the early stages of technology development. In particular, Popp (2002) finds clear evidence of significant within-technology knowledge spillovers for eleven different energy technologies, as well as the evidence of diminishing returns to research in a given field, suggesting that it

\footnotetext{
${ }^{11}$ Johnstone and Hascic (2010) find evidence that innovation in storage technologies increases innovation in intermittent technologies, such as solar, wind, and ocean, more than innovation in dispatchable technologies, such as geothermal, hydro and biomass.
} 
becomes increasingly difficult to add new innovations to the knowledge stock. ${ }^{12}$ More importantly, his evidence suggests that the effect of existing knowledge stocks on patenting activity substantially exceeds the effect of changes in energy prices: the change in patenting activity as a result of the average yearly change in energy prices is 'just' 2.05 percent; while the change in patenting activity attributed to the average yearly changes in the knowledge stock is 24.3 percent.

\section{Figure 3 Citation types encountered in citing patents in the field of renewable energy}

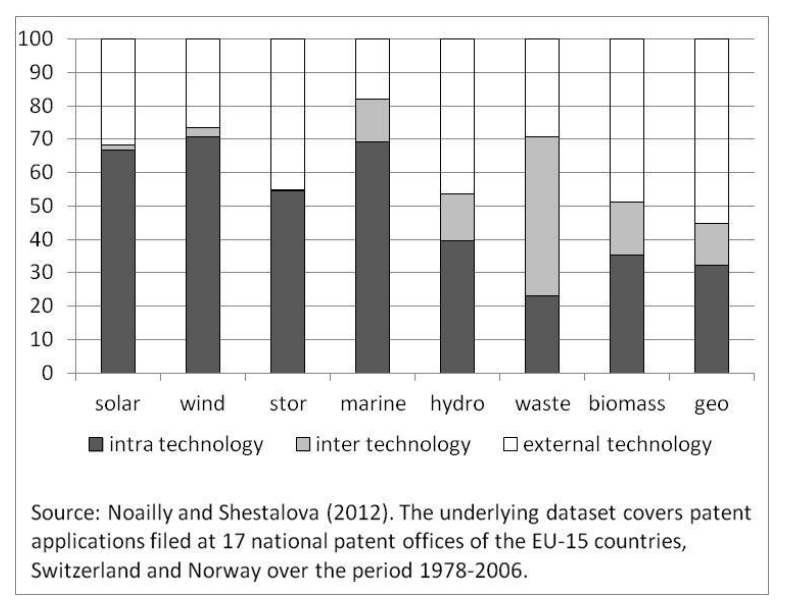

More recently, Noailly and Smeets (2012) confirm the conjecture that innovation in renewable energy technologies builds to a large extent on previous research in renewables, and thus possesses the 'standing on the shoulders of giants' feature. Moreover, Noailly and Shestalova (2012) show that the degree of path-dependency differs across renewables. Using patents citations, they measure the relative size of knowledge spillovers by counting the references to prior art included in patents. The analysis covers two broad knowledge fields: 'renewables' (REN) and 'fossil-fuel' (FF). The REN-field includes solar, wind, hydro, marine, waste, biomass, geothermal, and storage technologies, ${ }^{13}$ while the FF-field includes burners, furnaces, turbines, steam engine plants, steam generation, fuel-gas production by carbureting air, and ignition. Figure 3 displays RENtechnologies. For each technology, the bars show the relative contribution of backward citations that occur (i) within the same technology, i.e., intra-technology citations; (ii) from other REN or FF technologies, i.e., intertechnology citations; and (iii) from other knowledge fields that are not included in REN or FF, i.e., externaltechnology citations. We observe that REN-technologies mainly build on prior knowledge within the same field, as well as on 'external' knowledge, while there are comparatively few citations from other energy fields. Although the intra-technology citation category is, on average, the largest of the three, its size substantially differs across technologies. Furthermore, Noailly and Shestalova (2012) show that inter-technology citations in patents of hydro and marine technologies typically come from REN-technologies, while inter-technology

\footnotetext{
12 These technologies are: coal liquefaction producing liquid fuels, coal gasification producing gaseous fuels, solar energy, batteries for storing solar energy, fuel cells, using waste as fuel, recovery of waste heat for energy, heat exchange: general, heat pumps, Stirling engines and continuous casting processing of metal.

${ }^{13}$ Storage (namely: batteries for electric storage) has been included because of its importance for the development of intermittent energy sources.
} 
citations in biomass and waste technologies typically come from FF-technologies. All this suggests that the degree of path-dependency substantially differs across energy technologies.

\subsection{Uncertainty and asymmetric information}

Another important factor affecting policy choice in clean power-generating technologies relates to the degree of information asymmetry between firms and governments, as well as to the degree of information uncertainty faced by both these parties.

In particular, with respect to the information asymmetry between firms and governments, the common view in the innovation literature is that innovating firms typically have superior information on both the expected costs and benefits of innovations. ${ }^{14}$ Although this common view remains unchallenged in many markets, we argue here that the particulars of innovations in electricity generation technologies are such that the informational disadvantage of the government, especially with respect to innovation benefits, is less than in some other sectors of the economy. The reason for this is that most innovation in electricity generation is ultimately directed at reducing the production cost of electricity, rather than at creating a new commodity. Indeed, the basic commodity for sale in the electricity market, a $\mathrm{kWh}$, has remained unchanged since the California Electric Light Company in San Francisco started selling electricity to its customers in 1879. Although consumers differ in their environmental awareness and may prefer one clean technology over another, this heterogeneity in consumer tastes is unlikely to create a substantial informational advantage for the suppliers of particular technologies over other suppliers and the government with respect to the expected market demand for different technologies. ${ }^{15}$ Besides, the benefits of clean technologies over dirty technologies depend largely on environmental policy stringency worldwide. Consequently, both the private value of innovations in any particular electricity generation technology will depend mainly on the price-cost advantage of that technology versus other technologies. Concerning this type of information, firms innovating in a particular field may still have superior information on their own innovation strategies and on the prospect for specific clean technologies. For example, firms may have superior information regarding the prospect for cost decreases in solar PV vis-à-vis carbon capture and storage. Notice, however, that this superior information on the prospect for a specific technology may fail to 'translate' into superior information in terms of the private benefits of the innovation: firms may not capture the gains of 'early' innovations in electricity generation technologies, because demand for these innovations during the patent lifetime is negligible.

Another and perhaps even more important information problem in the energy sector concerns uncertainty (for all parties) about potential price shocks that may affect specific power-generating technologies, as well as about the potential for cost reductions in different technologies. Indeed, the IEA (2010a, p.20) observes that it is

\footnotetext{
${ }^{14}$ See, for example, Wright (1983) and the references cited there.

${ }^{15}$ A niche of consumers may display preferences for a specific source of non-polluting electricity. For instance, some consumers may still prefer solar electricity over the electricity generated from fossil-fuel, even if the latter technology incorporates carbon capture and storage. In this article, we ignore such technology-specific preferences. However, our conclusions will still hold as long as these groups are likely to be small.
} 
impossible to make 'any generalization on costs above the regional level; but also within regions [...], and even within large countries [...], there are large cost differences depending on local cost conditions [...].' Moreover, the IEA (2010a, p.20) notes that the 'cost for renewable energy technologies shows important variations from country to country and, within each country, from location to location.' This suggests that some part of the existing variation in cost estimates of electricity generation technologies can be attributed to fluctuations in prices for plant components and key commodities, which may be unknown to firms as well. ${ }^{16}$ Hence, although firms are likely to have some superior private information over the government (e.g., on local conditions or their own capacity in inventing or adopting a new technology), yet, both firms and the government face uncertainty attributable to unexpected price shocks and other market developments.

To learn what is known with respect to the information about the potential for cost reductions of powergenerating technologies, we can turn to the literature that estimated the relationship between costs and the installed capacity (indicating learning by doing), R\&D expenditures (indicating learning by research), or both. This literature reveals that both learning-by-doing and learning-by-research contribute substantially towards the cost decrease of electricity generation technologies over time. ${ }^{17}$ However, the estimated learning rates tend to display substantial variation both between technologies and between studies. ${ }^{18}$ In part, this variation can be explained by differences in the assumed geographical domain of learning (Lindman and Söderholm, 2011) as well as by econometric methodology (Söderholm and Sundqvist, 2007). However, a substantial part of this variation may also be genuine, simply reflecting the current, imperfect state of public knowledge about these technologies of both firms and governments.

This raises the question whether the imperfect state of public knowledge represents a reflection of uncertainty or of the fact that policy makers know less than private firms. To us, both 'explanations' seem to have at least some merit: although innovating firms may have superior information regarding the near future of electricity generation technologies (since they know more about their own research strategies), they are unlikely to have superior information regarding more distant future of electricity generation technologies, or about undiscovered breakthrough technologies, such as nuclear fission, which are unknown to all parties. Furthermore, as argued by Smith (2008), even if all the technical information were available (or could be acquired), it would still be

\footnotetext{
${ }^{16}$ Another illustration of the extent of cost fluctuations is provided by Davis (2011), who observes that overnight construction costs (i.e., the present value cost that would have to be paid as a lump sum up front to completely pay for a construction project) for nuclear seem to have risen with $26 \%$ within a single year, from 2009 to 2010.

${ }^{17}$ In the discussion of relevant policy options in Section 4, we will mainly focus on learning-by-research for the reasons of clarity; however, we do not intend to de-emphasize the importance of learning-by-doing in any way.

${ }^{18}$ Some notable contributions are: Klaassen et al. (2005) who estimate two-factor-learning curves for wind energy in Denmark, Germany, and the United Kingdom; Ek and Söderholm (2010) who estimate two-factor learning curves for wind power using a panel data set for five European countries; and Kahouli (2011) who estimates a two-factor learning curve for nuclear cost. Jamasb (2007) who estimates two-factor-learning curves for twelve fossil and non-fossil fuel technologies, observes that learning rates display substantial variation between technologies. Furthermore, Jamasb and Köhler (2008), Kahouli-Brahmi (2008), Lindman and Söderholm (2011) discuss differences across studies.
} 
challenging to use it properly in the context of big environmental problems, because these problems feature connected markets, feedback effects, and both price and non-price interactions.

All in all, this leads us to conclude that the design of innovation policy in the power sector is hampered by information problems, notably by different types of uncertainty (e.g., technical, economic, and political) and to some extent by information asymmetry. However, the extent of information asymmetry between the government and innovating firms in this market is less than in some other markets. A firm's private information concerns mainly its own innovation strategy and its estimates of prospects of specific clean technologies. By itself, this information advantage may be insufficient for yielding the firm a positive private value through innovation, because demand for these innovations during the patent lifetime is negligible.

\section{From generic to more specific innovation policy}

In this section, we discuss conditions under which a non-generic innovation policy may work better than generic policy. We will use our observations from Sections 2 and 3 to argue that a generic innovation policy is unlikely to be optimal for spurring innovations in clean power-generating technologies. However, we stress that the proposed move towards a less generic innovation policy is not a move to an extreme picking-the-winner type of policy either, because a certain amount of $R \& D$ diversification remains optimal, as long as electricity generation technologies are imperfect substitutes and learning about these technologies' costs is endogenous.

To fix ideas, let us think first about generic innovation policy, in which innovation in all electricity-generating technologies receive equal public support, for example an R\&D subsidy. An example of generic innovation policy in the electricity market would be the situation in which the government would allocate the same level of public R\&D support to both dirty and clean technologies (see Figure 4). In order to understand under which circumstances such a generic innovation policy may be suboptimal, we turn to Acemoglu et al. (2012), who argue for allocating R\&D subsidies to clean innovations only.

This recommendation of a more specific innovation policy originates from a combination of three assumptions. First, innovators have the ability to direct innovation at a specific sector, i.e., the clean or the dirty sector. Naturally, this ability to direct innovation is a crucial prerequisite for any non-generic innovation policy. Second, the clean and dirty inputs are gross substitutes in the production process, ultimately allowing for the replacement of dirty by clean inputs. Third, both the clean and dirty sectors are characterized by a sectorspecific knowledge accumulation process, which possesses the "standing on the shoulders of giants" feature. The latter means that advances in the clean sector make future advances in that sector more profitable or effective, in comparison to the advances in the dirty sector, and vice versa. Combined, these three assumptions imply the need for a non-generic R\&D policy, differentiating between the clean sector and the dirty sector. 


\section{Figure 4 Generic versus specific policies}

\begin{tabular}{ccc} 
Generic policy: & Differentiation & Additional \\
clean and dirty & between & differentiation \\
technology receive & clean and dirty & of clean \\
same support & technology & technologies \\
\hline
\end{tabular}

Extending the reasoning by Acemoglu et al. to incorporate multiple renewable technologies as 'sub sectors' within the clean sector may move us beyond a policy that supports all clean research equally, if we assume that the same three assumption will still hold for these sub sectors. In particular, let us make a further distinction between clean technologies, such as solar, wind, and concentrated solar power; and suppose that each of them is characterized by its own knowledge-accumulation process, building purely on the own technology-specific knowledge stock. Therefore, there are neither knowledge spillovers between clean technologies nor between the clean and dirty technologies (or these spillovers are negligible). Under these conditions, it may even be efficient to move 'beyond' an innovation policy that supports all clean research equally: this would entail a move from the second to the third point in Figure 4.

In the extreme, this logic could take us to an outright 'picking the winner' type of innovation policy, where all public support is directed at one technology only. However, this will not occur, because the drive towards a fully-specific innovation policy is counterbalanced by three factors. First, as stressed by Acemoglu et al. (2012), the case for moving towards an innovation policy supporting only clean research becomes weaker if there are (substantial) knowledge spillovers from dirty technologies to clean technologies. As shown by Figure 3, innovations in solar and wind technology build mainly on earlier innovations in the same technology, whereas innovations in waste and geothermal energy depend to a large degree on knowledge from other technologies. Therefore, more technology-specific policy may be beneficial for the solar and wind technology, but not for some other clean technologies. Second, imperfect substitution between electricity generation technologies speaks in favor of diversification of the investment portfolio, and hence, more generic innovation policy, which takes into account the uncertainty about potential cost reductions in alternative technologies (Blanford, 2009). Given that the marginal return on innovation falls with increased funding, it will be optimal to move funds away from (innovation in) technologies with low marginal returns to (innovation in) technologies with high marginal returns. Notice, that in cases where two technologies, such as solar PV and storage, are complementary to each other, diversification of the investment portfolio (and a more generic innovation policy) will be the natural outcome. Finally, the possibility of active learning about the cost of clean technologies also speaks in favor of a more generic innovation policy (Guo, 2011). Guo shows that the optimal R\&D portfolio balances the benefits and costs of experimenting with technologies, which recognizes 'the informational return from experimental investments, stressing the idea: the more you invest, the more you learn' (Guo, 2011, p.42). The optimal research portfolio will thus change over time, based on the revealed information about knowledge spillover and 
changes in the relative costs of clean technologies. Notice that, although the mechanism behind this result is closely connected to the standard option-value recommendation of 'wait-then-invest' (Dixit and Pindyck, 1994), its recommendation is diametrically reversed. Whereas traditional option value theory recommends postponing investment until new information arrives, active learning requires investment in multiple technologies in order to generate new information on their future cost.

Therefore, we conclude that although these factors increase the likelihood that all technologies should be supported by innovation policy, they keep open the possibility that optimal innovation policy needs to be more heavily concentrated at a few technologies only. Yet, more knowledge must be accumulated to enable a more specific policy. Portfolio approach (i.e., a portfolio of technologies, see Pugh et al. (2011) for a description of two analytical approaches to energy $R \& D$ portfolio) can help facilitate active learning about the costs of technologies.

\section{Alternative policy options for directing technical change in the power sector}

In this section, we evaluate the potential of alternative innovation policy instruments for spurring clean innovations. We limit the discussion to the three policy alternatives that we introduced in Section 2: (i) providing public R\&D to innovations in clean technologies; (ii) modifying patent protection; and (iii) raising the price of carbon emissions above its first-best level. However, now we will analyze these policies in the presence of the key characteristics of the electricity sector described in Section 3, because of which we keep open the possibility of a more technology-specific policy. Furthermore, we discuss potential issues with respect to practical implementation of these policies, such as their design issues and lack of international coordination of these policies. Our extended analysis suggests that the first option - providing public R\&D - has the largest potential for spurring clean innovations.

\section{$5.1 \quad$ Public R\&D support}

The possibility to realize a non-generic innovation policy depends crucially on the possibility to link policy instruments to innovations in specific technologies. Public R\&D allows for such differentiated support to different technologies. Note that public R\&D comprises different types of instruments, including both ex-ante instruments (e.g., traditional R\&D subsidies), ex-post rewards (e.g. discovery prizes), or other instruments (e.g. matching mechanisms of allocating subsidies). So far, public R\&D has been mainly applied in the form of subsidies. ${ }^{19}$ The empirical evidence suggests that $R \& D$ subsidies are an effective instrument in spurring innovation in electricity generation technologies. For example, based on a patent data of 25 countries over the period of 1978-2003, Johnstone et al. (2010) find that technology-specific R\&D subsidies have a significant and sizeable effect on innovation in wind, solar, and geothermal. Extending the analysis of Johnstone et al. to include fossil-fuel technologies, Hascic et al. (2009) find a positive effect of technology-specific R\&D subsidies targeted at different renewable and fossil-fuel technologies. Lanzi and Sue-Wing (2010) also find a positive effect of public $R \& D$ on energy-technology patents. The productivity ratio between $R \& D$ funding devoted to fossil energy and to renewable energy was estimated at 0.29 , implying that clean $R \& D$ is relatively more

\footnotetext{
${ }^{19}$ See IEA (2006) for an overview of energy R\&D policy in IEA countries.
} 
productive. Furthermore, Dechezlepretre and Glachant (2011) find that public R\&D directed at innovation in wind technology is more efficient in inducing innovation than other environmental policies, such as feed-in tariffs and standards.

So far, mainly R\&D subsidies have been used as an instrument to allocate public R\&D between firms. However, at least in theory, governments may also use ex-post mechanisms (e.g. prizes) as an alternative to R\&D subsidies. This reduces the risk of government failure that may arise due to information asymmetry between firms and the government, because prizes utilize private information on research cost or the probability of success by conditioning the innovator's remuneration on the information revealed ex post. To their disadvantage, prizes may initiate a patent race among firms, thus, leading to excessive R\&D spending. However, given the current level of R\&D expenditures on clean technologies (IEA, 2010b), this problem is unlikely to be substantial in practice. Although prizes have not been used in the electricity sector, there is some scarce evidence on their positive effects in other sectors. ${ }^{20}$ A commonly heard objection to prizes is the difficulty in specifying the goal or victory conditions. Notice, however, that this is less relevant for innovation in electricity generating technologies: electricity is a relatively homogeneous product; therefore, the conditions that need to be satisfied by contestants are relatively straightforward to define in technical terms. These technical requirements include the maximum production costs of a new technology, its carbon-reducing potential, and its flexibility in serving demand. This makes prizes to be a suitable instrument in this sector, provided their proper design. $^{21}$

Note that the empirical evidence on effects of public subsidies provided by national governments, which was discussed in the beginning of this section, suggests that public R\&D policies may be effective in spurring innovations even without explicit international cooperation in setting-out these policies. However, given the global nature of the climate problem, international cooperation on climate policy is likely to further increase both patenting and diffusion of clean innovation (Volleberg and van der Werf, 2012). Therefore, as for any policy instrument, international coordination of public R\&D policies in the power sector may improve welfare.

Notwithstanding their suitability, public R\&D, and especially non-generic R\&D policy, raises a number of design issues, such as the choice of the technological portfolio (see Section 4) and the standard agency problems of moral hazard and adverse selection (Laffont and Tirole, 1993). More complex R\&D policies may thus be more prone to government failure. ${ }^{22}$ Therefore, governments should balance the benefits of non-generic R\&D support against the incurred costs of government failure. An important potential government failure

\footnotetext{
${ }^{20}$ E.g. Williams (2010) reports a positive effect of prizes on innovation in agriculture and pharmaceuticals.

${ }^{21}$ We refer to Newell and Wilson (2005) for a profound discussion of several other design issues for technology prizes, including the determination of the financial award.

${ }^{22}$ Lerner (2009) provides numerous examples of government failure in attempts to carry out specific innovation policy, distilling two main reasons for the failure of government programs. First, governments can simply 'get it wrong', allocating funds in a counterproductive manner; second, regulatory capture can derail a government program. With respect to wind energy, Klaassen et al. (2005) show that inconsistency between policies intended to stimulate innovators and policies directed at the adoption of these innovations may deter innovations.
} 
acknowledged in the economic literature relates to crowding out of private investment. For example, the empirical evidence presented by Popp (2002) suggests that R\&D polices before the Reagan Administration resulted in crowding out of private $\mathrm{R} \& \mathrm{D} .{ }^{23}$ In theory, the crowding out effect can be decreased if the government uses incentive-compatible ways of allocating R\&D-subsidies, in order to reveal private information. Examples of such incentive-compatible schemes are matching mechanisms, in which the size of R\&D subsidies depends on the firm's own investment (Maurer and Scotchmer, 2004). In addition, the matching requirement induces larger effort, as well as screens out less capable firms, for which the investment in innovation would yield a smaller gain. Naturally, the use of matching mechanisms requires that innovation in electricity generation technologies is privately profitable with the subsidy.

Based on the discussion in this section, we conclude that public R\&D has several advantages that make it a suitable policy instrument for spurring clean innovations. However, the risk of design errors is increasing when policy becomes more specific, which requires a very careful consideration of the exact policy design.

\subsection{Modifying patent protection}

As a next step, we discuss the option of modifying the current patent system to internalize the knowledge spillovers arising from innovation in clean electricity generation technologies. We will argue that this option may not offer a practically-feasible solution to spurring clean innovations.

Let us first discuss what types of modifications are needed in order to implement a more specific innovation policy. Since the positive externality is primarily on future innovators, an improved patent system would have to involve a payment from future innovators in a particular technology, e.g. solar PV or wind, to the current innovator. Acemoglu (2011, pp. 22) notes that current patents do not have this feature: 'once a new product or procedure is deemed to pass the originality requirement, it does not have to pay royalties to the innovators of the previous leading-edge technology, let alone to all innovations that invented the technologies that preceded the previous one.' In this setting, strengthening patent protection means that patents should be made sufficiently broad and long. ${ }^{24}$ In particular, Green and Scotchmer (1995) show that the patent length and patent breadth play different roles in rewarding sequential innovators: the length defines total profits accruing to innovators and the patent breadth allocates these profits between them. ${ }^{25}$

Although stronger patent protection may in theory spur innovations (which was the case in our example in Section 2), it may be insufficient for spurring innovations in practice. For example, strengthening patent

\footnotetext{
${ }^{23}$ Another concern is the crowding out of R\&D from other sectors. However, according to Popp and Newell (2012), who analyze this effect, increases in energy R\&D do not draw R\&D resources away from sectors that do not perform energy $\mathrm{R} \& \mathrm{D}$; and despite an increase in alternative energy patents leads to a decrease in other types of patenting activity, this is due to profit-maximizing changes in research effort, rather than financial constraints that limit the total amount of R\&D possible.

${ }^{24}$ Note that in Section 2 we have assumed that the second innovation is always infringing on the first innovation, therefore, we focused only on the effect of patent length on innovation.

${ }^{25}$ See Scotchmer (2004) for more detail on the current patent system and a summary of the theoretical literature.
} 
protection in Japan in the late 1980s has not resulted in an increase of R\&D or innovations (Sakakibara and Branstetter, 2001), and stronger patents in the U.S. software industry actually reduced R\&D spending relative to sales (Bessen and Hunt, 2004). This 'paradoxical' outcome is likely to be attributed to the role of patent protection in knowledge transfer from early innovators to follow-on innovators. Therefore, the strength of patent protection should be related to the possibility of licensing and/or the cooperation between firms (Scotchmer, 1991). ${ }^{26}$ For instance, without increased possibilities for licensing, stronger patents would encourage first generation products, but might discourage second-generation products (which might then fire back and lead to less first-generation innovations in cases where innovation is sequential). Bessen and Maskin (2009) argue that licensing failure is likely to remain a problem if innovation is both sequential and complementary. In their setting, 'if patent holders are not well-informed about a rival's potential future profit as the rival is himself, she may have difficulty setting a mutually profitable license fee, and so, [...] licensing may fail' (p.613). Notice that licensing failure is likely to be a larger problem in rapidly developing industries (see e.g., Bessen and Meurer (2008) on litigation problems in computers or semiconductors).

Another reason for licensing failure relates to the lack of coordination in the licensing behavior of the owners of complementary basic innovations (so-called 'research tools'). In particular, if complementary research tools are needed as inputs for a follow-on innovation, uncoordinated actions of research-tool owners may result in too high license prices, thereby reducing incentives for follow-on innovations. This problem is known as a 'problem of anti-commons' (Shapiro, 2001). In theory, markets can solve the latter problem by means of a joint ownership of basic research tools in the form of a patent pool, which is a consortium of at least two companies agreeing to cross-license patents relating to a particular technology. However, patent pools may also discourage innovations when they reduce the intensity of market competition (Lerner and Tirole, 2004). Moreover, the evidence on patent pools that were formed in the 1930s (which was the last 'golden age' of patent pools before the current period) shows that there was typically a decline in innovation activities after the formation of the pool. Moreover, the decline was the strongest in industries where more than one pool member was an active inventor before the creation of a pool (Lampe and Moser, 2011). ${ }^{27}$ Since the electricity industry is characterized by multiple innovators in each technology, this finding casts doubt on the expectation of an improved innovation prospect under patent pools.

Next to the increased adverse effect of license failure under stronger patent protection, another problem is that the practical implementation of stronger patent protection would require international coordination. Indeed, recent empirical evidence points to the presence of international spillover effects in the patent market (Dekker et al., 2011). Because the market for innovations in electricity generating technologies is an international market, changes in patent protection would need to be made internationally. Since national markets for innovations (or even a European market) are relatively small in comparison to global markets, changing patent protection in a single economy is ineffective for spurring domestic innovations in internationally tradable products and

\footnotetext{
${ }^{26}$ Besides, longer patents may also reduce knowledge diffusion to producers.

${ }^{27}$ Based on evidence of patent pools in twenty industries formed in the period 1930-1938, including the power industry.
} 
technologies. For example, based on a dataset of 26 countries covering 1978 to 2002, Qian (2007) shows that national patent protection has little effect on domestic innovative activities in pharmaceuticals. ${ }^{28}$

Recognizing the complexity of theoretical issues and practical challenges arising with respect to reinforcing patent protection at a national and an international level (see, e.g., OECD, 2004), we conclude that stronger patent protection is unlikely to be an attractive option for implementing more specific innovation policy.

\subsection{Raising carbon emission prices}

As an alternative to providing public R\&D support, governments might also raise carbon taxes above their efficient, first-best level. ${ }^{29}$ In particular, empirical evidence shows that (especially high) carbon taxes spur innovative activity in the electricity sector. ${ }^{30}$ Notwithstanding the observed positive effect of higher taxes on clean innovation, we will argue in this section that emission taxes are, by their very nature, an ill-suited instrument for implementing non-generic innovation policy in the electricity sector.

First, we note that since carbon emission taxes reward clean innovations by increasing the price of electricity, they internalize knowledge spillovers for 'low-cost' renewables (that are profitable under the carbon tax), but not for 'high-cost' renewables (unprofitable under this tax). Secondly, carbon taxes are unable to reflect differences in knowledge spillovers between innovations. Furthermore, besides their inability to efficiently internalize knowledge spillovers, higher current carbon taxes would also create a greater reduction of current production and consumption, thereby increasing the cost of climate policy. For the economy as a whole, Acemoglu et al. (2012) suggest that the associated welfare loss of raising carbon taxes vis-à-vis the optimal policy - a policy, which comprises efficient carbon taxes and subsidies to clean research - lies between 1.02 and

\footnotetext{
${ }^{28}$ Note the difference with the case of public R\&D. A lack of international coordination does not hamper effective unilateral changes in public R\&D policies, although coordination of R\&D policies would spur innovations.

${ }^{29}$ Here we focus on carbon taxes, and do not consider tradeoffs between taxes and other ways of increasing private costs of emissions, such as tradable pollution permits, emission standards, or quota's, can be considered instead. All these mechanisms would be equivalent, if we ignored innovation, imperfect knowledge and uncertainty about the pollution costs and benefits. However, under uncertainty, either price or quantity mechanisms may be preferable depending on the curvature of costs and benefits (Weitzman, 1974). Similarly, these instruments are also inequivalent in the presence of innovation. Theoretical papers considering innovations in the context of environmental policies (e.g., Laffont and Tirole, 1996, and Montero, 2011) suggest that the relative ranking of carbon taxes and permits may also depend on the type of innovation (pollution-free or pollution reducing) and the degree of the government commitment to these environmental policies. These papers show that complementing taxes or permits with an additional innovation policy may be welfare improving.

${ }^{30}$ Popp (2002) shows that higher taxes induce more innovations in the energy sector. Moreover, recent empirical evidence confirms that high taxes also shift patenting activity from energy-efficient fossil technologies towards clean technologies (Aghion et al., 2011; Hascic et al., 2009; Lanzi and Sue-Wing, 2010; Noailly and Smeets, 2012). Furthermore, ample empirical evidence confirms that higher taxes (and more stringent environmental policies in general) are indispensable for the adoption of clean technologies (see Vollebergh, 2007 for a review).
} 
3.15 percent of GDP. ${ }^{31}$ In the electricity sector, higher carbon taxes would imply a (too fast) forced write-down of existing fossil-fuel generation capacity, which would be replaced by more expensive clean electricity generation technologies too early.

In addition to creating welfare losses, spurring innovation by raising carbon taxes necessarily requires cooperation between the world's major polluters, as these economies are the world's major markets for new clean electricity generation technologies. Therefore, the economic advantage of clean technologies over dirty technologies depends largely on environmental policy stringency worldwide, since it is the global carbon tax that counts, not the carbon tax in the EU or any single country. ${ }^{32}$ On the one side, more stringent environmental policies by some countries impact knowledge flows, facilitating clean technology diffusion to other countries (e.g., Lovely and Popp, 2011). On the other side, coordinating environmental policies spurs innovation itself (see, for example Vollebergh and van der Werf (2012) on the effect of international standards on patenting activities). ${ }^{33}$ Otherwise, the market for clean generation technologies would remain relatively small, as would the private value of early innovations in electricity generation technologies. Considering the current reluctance of many governments to sign even a moderate environmental agreement, large increases of carbon taxes worldwide are probably infeasible, especially in the short run. Therefore, the option of raising taxes above the efficient level is probably infeasible as well.

This is not to say that we should 'disregard' taxes (and other environmental policies meant to internalize the environmental damage by polluters) and the respective international environmental agreements. Ultimately, they are needed to create the markets for clean electricity generation technologies, when the cost of these technologies eventually decreases due to innovation policy. Therefore, efficient carbon emission taxes, reflecting the marginal damage, should always be a part of the policy for clean innovations. We conclude that, since the current taxes are often low or simply non-existent in a large part of the world, it would be optimal to raise them to reflect the marginal damage. However, raising carbon taxes above that level is inefficient and probably also infeasible, given the international dimension of the problem.

\section{Conclusion}

In this paper, we have argued that generic innovation policy is likely to be suboptimal to spur innovation in clean electricity generation technologies. This is the fundamental insight of the paper by Acemoglu et al. (2012). The key underlying issue is that the existing cost differential between clean and dirty technologies, for example, between solar PV and coal-fired generation, cannot be bridged within the lifetime of a patent. This makes innovations in clean technology, such as solar PV, privately unprofitable. Hence, optimal R\&D policy

\footnotetext{
${ }^{31}$ The variation in these numbers is due to variations in both the utility discount rate (pure rate of time preference) and the elasticity of substitution between dirty and clean technology.

${ }^{32}$ Dekker et al. (2011) show that both national and international pollution regulations have had significant effects on patenting activities for $\mathrm{SO} 2$ patents.

${ }^{33}$ In addition to policy stringency, also the degree of government commitment to the policy is important for private value. See, e.g., Boyer and Laffont (1999), Brunner et al. (2011), and Requate (2005).
} 
must - at least to some extent - differentiate between innovations in dirty and clean technologies, and perhaps even between innovations in different clean technologies. Naturally, the lingering question is how to design such non-generic innovation policies.

As a first step, we have characterized technical change in electricity generation technologies, stressing that there exists considerable heterogeneity in knowledge spillovers within clean technologies. Whereas the share of within-technology patent citations is almost 60 percent for wind and solar PV, this share is only 20 percent for waste and geothermal. Moreover, we have argued that due to the absence of innovation in the electricity commodity itself (i.e., in the $\mathrm{kWh}$ for sale), an important impediment for non-generic innovation policy is absent in this sector, since the information advantage of innovating firms over the government with respect to the market demand for clean electricity is limited. In addition, the private value of many patents in still expensive, barely used technologies, such as concentrated solar power, is currently small, possibly, zero. This means that the current patent protection is insufficient to spur innovations at least in some clean technologies and stresses the need for additional policy support towards innovation in these technologies. This implies the need for non-generic innovation policies in this sector, such as policies differentiating between clean and dirty technologies and perhaps even between certain clean technologies.

Four factors counterbalance this drive towards more specific innovation policy. First, the presence of knowledge spillovers between technologies may also weaken the case for more specific policy. The second factor relates to the decreasing returns to scale and resource constraints of electricity generation technologies, which implies that these technologies are imperfect substitutes. Given that the marginal return on innovation falls with increased funding, it will be optimal to move funds away from (innovation in) technologies with low marginal returns to (innovation in) technologies with high marginal returns. Notice, that in cases where two technologies, such as solar PV and storage, are complementary to each other, diversification of the technology portfolio (i.e. supporting both complementary technologies) and a more generic innovation policy will be the natural outcome. The third factor is related to the necessity of active learning about the future cost of clean electricity generation technologies. Diversification of the research policy delivers information on the potential for future cost reductions in specific electricity generation technologies. As this information is valuable, it pays to invest in all technologies, even if some of them have very low expected returns. Therefore, the optimal R\&D portfolio should recognize that: i) diversification is (at least to some extent) necessary; ii) knowledge spillovers differ both within and between technologies; and iii) the payoff to R\&D investments remains uncertain. Finally, making innovation policy more specific increases the risk of government failure, including those related to moral hazard and adverse selection. In part, the social costs related to government failure may be offset by turning to incentive compatible instruments, such as prizes and matching (of subsidies). Alternatively, policy makers may use menus of emission taxes and subsidies to reduce government failure (cf. Arguedas and Van Soest, 2009). Notwithstanding these drawbacks of more specific innovation policy, we argued that public R\&D, in combination with carbon taxes set at the efficient level and standard patent protection, are the most suited instruments for spurring innovations in the power sector: both stronger patents and higher carbon taxes will only spur clean innovations if they are applied internationally, which will delay their implementation. While public $\mathrm{R} \& \mathrm{D}$ policies would also benefit from international effort coordination, they are able to spur clean innovations 
even when applied only at (supra)national levels, thus, speeding up the development of clean technologies. In addition, stronger patents are hampered by licensing failure and raising current carbon taxes lead to the premature deployment of high cost electricity generation technologies, which reduces welfare. 


\section{References}

Acemoglu, D., 2011, Diversity and Technical Progress, NBER Working Paper 16984, NBER, the USA.

Acemoglu, D., P. Aghion, L. Bursztyn, D. Hemous, 2012, The Environment and Directed Technical Change, American Economic Review, 102(1), 131-166.

Aghion, P., A. Dechezlepretre, D. Hemous, R. Martin, J. Van Reenen, 2011, Carbon taxes, Path Dependency and Directed Technical Change: Evidence from the Auto Industry, working paper.

Arguedas, C., and D. P. van Soest, 2009, On Reducing Windfall Profits in Environmental Subsidy Programs, Journal of Environmental Economics and Management, 58, 192-2005.

Bessen, J., R. M. Hunt, 2004, An Empirical Look at Software Patents, Federal Reserve Bank of Philadelphia Working Paper 03-17.

Bessen, J., E. Maskin, 2009, Sequential innovation, patents, and imitation, RAND Journal of Economics, 40 (4), 611-635.

Bessen, J., M. Meurer, 2008, Patent failure: how judges, bureaucrats and lawyers put innovators at risk, Princeton, N.J: Princeton University Press.

Blanford, G.J., 2009, R\&D Investment Strategy for Climate Change, Energy Economics, 31, S27-S37.

Bollen, J., B. Guay, S. Jamet, J. Corfee-Morlot, 2009, Co-Benefits of Climate Change Mitigation Policies: Literature Review and New Results, OECD Economics Department Working Paper 693, OECD, Paris, France.

Bovenberg, L., S. Smulders, 1995, Environmental Quality and Polluting-Saving Technological Change in a Two-Sector Endogenous Growth Model, Journal of Public Economics, 57 (3), 369-91.

Bovenberg, L., S. Smulders, 1996, Transitional Impacts of Environmental Policy in an Endogenous Growth Model, International Economic Review, 37 (4), 861-893.

Boyer, M., J.-J. Laffont, 1999, Toward a Political Theory of the Emergence of Environmental Incentive Regulation, Rand Journal of Economics, 30 (1), 137-157.

Brunner, S., C. Flachsland, R. Marschinski, 2012, Credible commitment in carbon policy, Climate Policy, 12(2), 255-271.

Davis, L., 2011, Prospects for nuclear power, NBER Working Paper 17674, National Bureau of Economic Research, The USA.

Dechezlepretre, A., M. Glachant, 2011, Does foreign environmental policy influence domestic innovation? Evidence from the wind industry, Centre for Climate Change Economics and Policy and Grantham Research Institute on Climate Change and the Environment working papers, 44.

Dekker, T., H. Vollebergh, F. de Vries, C. Withagen, 2011, Inciting Protocols, Journal of Environmental Economics and Management, forthcoming.

Dixit, R.K., R.S. Pindyck, 1994, Investment under Uncertainty, Princeton University Press, The USA.

Ek, K., P. Söderholm, 2010, Technology learning in the presence of public R\&D: The case of European wind power, Ecological Economics, 69, 2356-62.

Gerlagh, R., S. Kverndokk, K.E. Rosendahl, 2009, Optimal timing of climate change policy: Interaction between carbon taxes and innovation externalities. Environmental and Resource Economics, 43(3), 369-390.

Green, J. R., S. Scotchmer, 1995, On the division of profit in sequential innovation, RAND Journal of Economics, 26, 20-33. 
Golombeck, R., M. Greaker, and M. Hoel, 2010, Carbon taxes and innovation without commitment, The B.E. Journal of Economic Analysis and Policy, 10 (1), 32.

Goulder, L.H., K. Mathai, 2000, Optimal $\mathrm{CO}_{2}$ Abatement in the Presence of Induced Technological Change, Journal of Environmental Economics and Management,39, 1-38.

Guo, C.L. 2011, A Bayesian Approach to Energy R\&D Portfolio Analysis, working paper of UCSB, The USA.

Hascic, I., N. Johnstone, E. Lanzi, 2009, The determinants of innovations in electricity generation technologies, working paper.

IEA, 2006, Energy Policies of IEA Countries: Review, International Energy Agency.

IEA, 2009, World Energy Outlook, International Energy Agency.

IEA, 2010a, Electricity information 2010. Technical report. International Energy Agency.

IEA, 2010b, Global Gaps in Clean Energy R\&D, IEA Report for the Clean Energy Ministerial, International Energy Agency.

IEA, 2011, $\mathrm{CO}_{2}$ Emissions from Fuel Combustion: Highlights, International Energy Agency.

Jaffe, A.B., R. G. Newell, R. N. Stavins, 2005, A tale of two market failures: Technology and environmental policy, Ecological Economics, 54, 164- 174.

Jamasb, T., J. Köchler, 2008, Learning rates for energy technology: a critical assessment, in Delivering a Low Carbon Electricity System Technologies, Economics and Policy, Eds. M. Grubb, T. Jamasb, M.G. Pollitt, Cambridge University Press, the UK.0

Jamasb, T., 2007, Technical change theory and learning curves: patterns of progress in electricity generation technologies, Energy Journal, 28 (3), 51-72.

Johnstone, N., I. Hascic, 2010, Directed technological change while reducing the risk of (not) picking winners: the case of renewable energy, working paper, OECD, Paper presented at the 2011 AEA Annual Meeting in Denver, January 2011.

Johnstone, N., I. Hascic, D. Popp, 2010, Renewable energy policies and technological innovations: evidence based on patent counts, Environmental Resource Economics, 45, 133-155.

Kahouli-Brahmi, S, 2008, Technological learning in energy-environment-economy modelling: A survey, Energy Policy, 36 (1), 138-162.

Kahouli, S, 2011, Re-examining uranium supply and demand: New insights, Energy Policy, 39 (1), 358-376.

Klaassen, G., A. Miketa, K. Larsen, T. Sundqvist, 2005, The impact of R\&D on innovation for wind energy in Denmark, Germany and the United Kingdom, Ecological Economics, 54, 227- 240.

Laffont, J.-J. and J. Tirole, 1993, A Theory of Incentives in Procurement and Regulation, MIT

Press, Princeton.

Laffont J.-J., J. Tirole, 1996, Pollution permits and environmental innovation, Journal of Public Economics, 62, 127-140.

Lampe, R, P. Moser, 2011, Do patent pools encourage innovation? Evidence from 20 industries in the 1930s, NBER discussion paper, http://ssrn.com/abstract=1967246

Lanzi, E., I. Sue-Wing, 2010, Directed technical change in the energy sector: an empirical test of induced directed innovation, working paper. 
Lerner, J., 2009, Boulevard of Broken Dreams. Princeton University Press, Princeton, The USA.

Lerner, J., J. Tirole, 2004, Efficient patent pools, The American Economic Review, 94 (3), 691-711.

Lindman, A., P. Söderholm, 2011, Wind power learning rates: A conceptual review and meta-analysis, Energy Economics. Available online 19 May 2011 (http://dx.doi.org/10.1016/j.eneco.2011.05.007).

Lovely, M., D. C. Popp, 2011, Trade, technology, and the environment: does access to technology promote environmental regulation?, Journal of Environmental Economics and Management, 61, 16-35.

Maurer, S., S. Scotchmer, 2004, Procuring Knowledge. In Libecap, G., ed., Intellectual Property and Entrepreneurship: Advances in the Study of Entrepreneurship, Innovation and Growth, Vol 15, pp. 1-31. The Netherlands: JAI Press (Elsevier).

Montero, J.P., 2011, A Note on Environmental Policy and Innovation when Governments cannot Commit, Energy Economics, 33(1), S13-S19.

Moraga-González, J. L. and N. Padrón-Fumero 2002, Environmental Policy in a Green Market, Environmental and Resource Economics, 22, 3, 419-447.

Newell, R., N. Wilson, 2005, Technology Prizes for Climate Change Mitigation, Discussion paper 05-33. Washington, DC: Resources for the Future, the USA.

Noailly, J., R. Smeets, 2012, Directing Technical Change from Fossil-Fuel to Renewable Energy Innovation: An Empirical Investigation Using Patent data, CPB Discussion paper, forthcoming.

Noailly, J., V. Shestalova, 2012, Innovation in renewable energy technologies: Lessons from patent citations, CPB Discussion Paper, forthcoming.

OECD, 2004, Patents, innovations and economic performance: OECD conference proceedings, OECD, Paris.

Popp, D., 2002, Induced innovation and energy prices, The American Economic Review, 92, 160-180.

Popp, D., 2004, ENTICE: Endogenous Technological Change in the DICE Model of Global Warming, Journal of Environmental Economics and Management, 48(1), 742-768.

Popp, D., 2006, ENTICE-BR: The effect of backstop technology R\&D on climate policy models, Energy Economics, 28, 188-222.

Popp, D., Newell, R. G., 2012. Where does energy R\&D come from? Examining crowding out from environmentally-friendly R\&D, Energy Economics, 34(4), 980-991.

Pugh, G., L. Clarke, R. Marlay, P. Kyle, M. Wise, H. McJeon, and G. Chan, 2011, Energy R\&D portfolio analysis based on climate change mitigation, Energy Economics, 33, 634-643.

Qian, Y., 2007, Do National Patent Laws Stimulate Domestic Innovation in a Global Patenting Environment? A Cross-Country Analysis of Pharmaceutical Patent Protection, 1978-2002, Review of Economics and Statistics, 89 (3), 436-453

Requate, T., 2005, Dynamic incentives by environmental policy instruments - a survey, Ecological Economics, 54(2-3), 175-195.

Sakakibara, M, L. Branstetter, 2001, Do stronger patents induce more innovation? Evidence from 1998 Japanese law reforms, Rand Journal of Economics, 32, 77-100.

Scotchmer, S., 1991, Standing on the shoulders of giants: cumulative research and the patent law, The Journal of Economic Perspecitives, 5(1), 29-41.

Scotchmer, S., 2004, Innovation and incentives, London: The MIT Press, The UK. 
Shapiro, C., 2001, Navigating the patent thicket: Cross licenses, patent pools, and standard setting," in A. B. Jaffe, J. Lerner, and S. Stern, eds., Innovation policy and the economy, volume 1, MIT Press for the NBER, $119-150$.

Smith, V. K. 2008, Reflections on the literature, Review of Environmental Economics and Policy, 2(1), 130145.

Söderholm, P., T. Sundqvist, 2007, Empirical challenges in the use of learning curves for assessing the economic prospects of renewable energy technologies, Renewable Energy, 32 (15), 2559-2578. http://dx.doi.org/doi:10.1016/j.renene.2006.12.007

Unruh, G. C., 2000, Understanding carbon lock-in, Energy Policy, 28, 817-830.

Unruh, G.C., 2002, Escaping carbon lock-in, Energy Policy, 30, 317-325

Vollebergh, H., 2007, Differential Impact of Environmental Policy Instruments on Technological Change: A Review of the Empirical Literature, Tinbergen Institute Discussion Paper Nr. TI 2007-042/3.

Vollebergh, H.R.J. and E. van der Werf, 2012, Standards for eco-innovation, mimeo.

Weitzman, M. L, 1974, Prices vs. Quantities, The Review of Economic Studies, 41(4), 477-491.

Williams, H., 2010, Incentives, prizes, and innovation, Mimeo MIT and NBER.

Wright, B., 1983, The economics of Invention Incentives: Patents, Prizes and Research Contracts, American Economic Review, 73, 691-707.

Zwaan, van der, B. C. C., R. Gerlagh, G. Klaassen, L. Schrattenholzer, 2002, Endogenous technological change in climate change modelling, Energy Economics, 24(1), 1-19. 
Publisher:

CPB Netherlands Bureau for Economic Policy Analysis

P.O. Box $80510 \mid 2508$ GM The Hague

$\mathrm{T}(070) 3383380$

October 2012 | ISBN 978-90-5833-570-8 